\title{
Recommendations on Herbs and Herbal Formula in Cancer Prevention
}

\author{
Rakesh Sharma* \\ Department of Engineering and Technology, Tallahassee Community College, Tallahassee, Florida 32304
}

\begin{abstract}
Herbs are naturally rich in bioactive herbiceuticals or plant products with food value to keep energy balance in the body and promise substantial therapeutic value in several diseases. Major herbs have specific active ingredient(s) with cancer therapeutic effects. Herbs are now part of nutrition supplements at nonprescription counters and their selfprescription has increased at large scale in hope of cancer prevention. The government agencies monitor and regulate the herbal use in cancer prevention and cancer management with update information of herbal side effects and safety to public. In present paper, different herbs are surveyed in the use of general health with an account of recommended potential herbs in cancer prevention. The biochemical mechanism of cancer prevention in tissues by herbs is proposed. Broadly herbs are rich in alkaloids, flavones, antioxidants, xanthones, omega-3 fatty acids, vitamins, minerals and fibers. Most of the herbs are derived from plants and they act as regulatory biochemical metabolites either by direct intermediary metabolism or regulating cancer pathways and stimulating immunity. The focus of review is to introduce available herbs, herbal biochemical action and herbiceutical anticancer formula. The herbal anticancer formula may be prepared by using: antiproliferative herb extracts combined with vitamin supplement, lactate dehydrogenase enzyme inhibitor, palliative alkalizing sodium or potassium salts as mixture in liquid, paste or syrup form. Herbiceuticals from herbs are potential anticancer supplements if used with care and regulatory guidelines.
\end{abstract}

Keywords: Herbiceuticals, cancer, immunity, metabolites, diet, cancer prevention, herbal supplementation.

\section{INTRODUCTION}

Herbs are natural form of whole plants or their parts such as flower, root, oil, stem rich in bioactive chemical compounds so called "Herbiceuticals". The main difference between pharmaceutic drug and herbal principles is their isolation method and purification level. The pharmaceutical drugs are available with high purity as artificial chemical(s) while herbs are in rich natural complex chemicals. Bioactive herbal principles (whole herbs, extracts or concentrates) may be used as "Bioactive herbal formulations" as combinations of different active chemicals of plants or their parts combined with known enzyme inhibitors, vitamins and alkalizing minerals that have value in health promoting, disease preventing or semi-medicinal properties. Herbal extracts may be fortified with vitamin, proteins, amino acids, minerals, carbohydrates. In 1994, United States implemented Dietary Supplement Health and Education Act (DSHEA) that sparked an upsurge in herbal use and continues today [1]. Different food companies have advocated their natural herbal products from herbs available from: (a) the food industry, (b) the herbal and dietary supplement, (c) pharmaceutical industry, and (d) the newly emerged bioengineered microorganisms, agroproducts or active biomolecules. It may range from isolated nutrients, herbal products, dietary supplements and diets to genetically engineered "custom" foods and processed products such as cereals, soups and beverages. Chemically the active components in bioactive herbs may be classified as isoprenoid

*Address correspondence to this author at the B222F, COE, 2525, Pottsdamer Street, Florida State University, Tallahassee, Florida 32310, USA;

E-mails: rksz2007@gmail.com, rksz2004@yahoo.com, rksz2004@gmail.com derivatives (terpenoids, carotenoids, saponins, tocotrienols, tocopherols, terpenes), phenolic compounds (couramines, tannins, lignins, anthrocynins, isoflavones, flavonones, flavanoids), carbohydrate derivatives (ascorbic acid, oligosaccharides, non-starch polysaccharides), fatty acid and structural lipids (n-3 polyunsaturated fatty acids PUFA, CLA, MUFA, sphingolipids, lecithins), amino acid derivatives (amino acids, allyl-S compounds, capsaicnoids, isothiocyanates, indols, folate, choline), microbes (probiotics, prebiotics) and minerals ( $\mathrm{Ca}, \mathrm{Zn}, \mathrm{Cu}, \mathrm{K}, \mathrm{Se}$ ) [2].

The present paper focuses on the introduction to available herbs for human use, their active ingredients, biochemical action of herbs and a simple proposed scheme of new herbal formula composition to design anticancer remedy according to the approved pharmaceutical limits for human use. The proposed herbiceutical scheme will serve as guide to design new formula for treating specific tissue cancer based on newly identified anticancer effects of specific ingredient(s) in proposed herb or mixture using sensitive biomarker tests of anticancer effect of new herbal formula. The hypothesis was that each herbal ingredient participates in normalizing the altered biochemical reactions in cancer tissue and active ingradient contributes its anticancer effects in cancer therapy so called 'herbal potency'. In design of anticancer formula, the mixture syrup or paste contains at least one antiproliferative herb, vitamins, lactate dehydrogenase inhibitor, alkalizing agent and sodium or potassium salts. For interested readers, a volume of evidences is presented in support of different well known herbs, their active ingradients, side effects and approved doses and current status approved by US government agencies: Centers of Disease 
Control (CDC) and Food \& Drug Agency (FDA). A present classification of herbs is presented as their herbal classification class 1 and $2 \mathrm{a}$ or $2 \mathrm{~b}$ approved by American Herbal Products Association's Botanical Safety Handout and Herbal Gram: American Botanical Council(AHPA-BSH); and Bundesinstitut fur Arzneimittel und Medizinproduckte. Complete German Commission E (BAMCGC) Monographs: The Therapeutic Guide to Herbal Medicines [3].

\section{HERBS AND THEIR PROPERTIES}

\section{Wild Yam (Dioscorea Villosa) or Black Root}

The herb is class I herb, rich in phytosterol such as diosgenin and serves as therapeutic effect on female hormone regulation and relief to menopause $[4,5]$. The diosgenin is antiproliferative and arrests $\mathrm{G} 2 / \mathrm{M}$ cycle with simultaneous downregulating NF-kappa B, Akt, cyclin D, c-myc to result with PARP enzyme cleavage and DNA fragmentation [6, 7].

\section{Blood Root (Sanguinaria Canadensis)}

It is known as AHPA-BSH class 2 herb but it is recommended less than $1 \mathrm{mg} / \mathrm{kg}$ human body weight. It is caustic agent and is part of "black salve or can- $X$ " made of zinc chloride with herbal ingradients. However it showed to have berberine, ouabain side effects of tissue corrosion, basal cell carcinoma. Some examples of blood root pharma products are sanguinarine, viadent.

\section{Taesal Root (Dipsacus Asper)}

It is AHPA-BSH class I herb anticancer formulation. Other uses are in lime disease, fibromyalgia, Alzheimer disease and available as product dose of 6-21 g/day for human use.

\section{Balm of Gilead Bud (Populus Balsamifera)}

It is AHPA-BSH class 1 herb. Its main use is in urinary infections, wounds, pain, and arthritis. However, side effects are liver inflammation, Reye's syndrome, brain damage.

\section{Frankincense (Boswellia Carteri)}

It is AHPA-BSH class 1 herb showing topoisomerase I and II inhibitor due to boswellic acid pentacyclic triterpene induced antiproliferation. Other action are: caspase 3/8/9 activation and PARP cleavage [8]; leukotriene/5lipoxygenase blocker. It is available as Boswellia serrata extract in capsule form of $400 \mathrm{mg}(\mathrm{x} 3)$ daily dose as anticancer remedy.

\section{Bakuchi Seeds (Cyamposis Psoraliodes)}

It is anticancer natural product safe for oral consumption available as bakuchi seed powder for leprosy, infections, tumors and baldness. FDA has warned for its use.

\section{Buckthrone Bark (Rhamnus Cathatica)}

It is APHA-BSH class 2 herb with anticancer properties. It also shows effective relief for intestinal cramps as laxative, constipation. However, it shows side effects of liver changes, mutagenesis, electrolyte imbalance [9]. FDA has warned for its use.

\section{Chaparral (Larrea Tridentate)}

It is APHA-BSH class 2 herb having tumoricidal properties and shows side effects of liver damage, renal disease [10]. However, its potentials as anticancer are not confirmed. FDA has warned for its use.

\section{Dichroa Root (Dichroa Febrifuga)}

It is potent anti-malaria agent available in does of 5-10 grams/daily. It is also reported as anti-cancer agent with antiinflammatory properties [11].

\section{Alkanet Root (Batschia Canescens)}

It is APHA-BSH class 2 herb containing toxic pyrrolizidine alkaloids, with promise as anticancer. Due to presence of alkaloids, the use is limited in human but used as coloring agents for oils, cosmetics, textiles, hair coloring. [12]. More investigations are needed for its use in human.

\section{Kochia Seed (Kochia Scoparia)}

It is aggressive tumbleweed, noxious seed with no known literature in human use. However, plant Kochia Hay is available for hepatotoxicity caused by saponins, oxalates and nitrates $[12,13]$. Its use is limited due to safety and efficacy in prior use.

\section{Kanta Kari (Solanum Xanthocarpum)}

It is common in India for asthma and respiratory infections without any known side effects. The herb is rich in salasodine with possible anti-fertility effects [14].

\section{Sweet Myrrh (Commiphora Molmol)}

It is APHA-BSH class 2 herb. It is used for infections, pain, swelling, leprosy with anti-inflammatory, antiparasitic, antioxidant properties [15]. Its use in schistosomiasis, Dicrocoelium dentriticum infections is administration of Myrrh for 3 days at $10 \mathrm{mg} / \mathrm{kg}$ was effective with no side effects on liver or kidney [16]. It is approved by German Commission E for tropical treatment such as inflammation. Other uses are of Myrrah are in apoptosis, antiproliferation in lung, pancreas, breast, prostate cancers under $500 \mathrm{ug} / \mathrm{ml}$ dose.

\section{Blue Cohosh Root (Caulophyllum Thalictroides)}

It is APHA-BSH class $2 b$ herb with tumoricidal properties and used for uterine contractions during labor. However, it can give side effects of myocardial infarction, tachycardia, stroke [17, 18]. The adverse side effects make its use limited.

\section{Male Fern Rhizome (Dryopteris Crassirhizoma)}

It is known as rich in kaemferol glycosides that can impair DNA polymerase and act as anticancer agents [19]. In in vitro cell lines, the plant extracts showed the fatty acid synthase enzyme inhibitor and arrested cancer growth through downregulation of PI3K/AKt and JNK pathways, S-phase arrest and resulting apoptosis [20, 21]. Little is known about its potentials in human use. It is common in treating tapeworms and influenza infections. 


\section{Garcinia Fruit (Garcinia Cambogia)}

It is rich in prenylated xanthones from mangosteen fruit with inhibitory properties against anti-neoplastic lesions in colon. [22]. It showed cytotoxic effects to leukemia, breast, gastric, lung, liver cancer cell lines. However, xanthones mediate anti-cancer effects through downregulation of cMYC mRNA expression/telomerase reverse transcriptase gene and initiate apoptosis, arresting immortalization, proliferation of human cancer cells [23]. Other component is garcinol, a polyisoprenylated benzophenone with capability of impairing unbridled cell proliferation by inhibiting nuclear histone acetyltransferase p300 and PCAF, capable of initiating apoptotic signaling in HeLa cells [24]. It arrested tumor cell proliferation, migration, cell adhesion, inhibition of MAPK/ERK, PI3K/Akt, membrane adhesion kinase phosphorylation, augmented expression of BAX, caspase $2 / 3$ activation, released cytochrome C, PARP-1 cleavage in human cancer cell lines [25]. Recommended dose of garcinia is 3-6 tablets per day of 500-1000 mg per tablet and considered potent and well tolerated.

\section{Vitex Powder (Vitex Agnus-Castus)}

It is APHA-BSH class $2 \mathrm{~b}$ herb and typically known as chasteberry or emmenagogue herb. It is widely known to cause homeopathic regulation of female endocrine system to ameliorate symptoms of PMS, amenorrhea, infertility, menopause due to estrogenic effects of phytoesterogens present in vitex [26], blocking production of prolactin from pituitary, shortening luteal phase and antagonizing hormonal imbalance(low progesterone synthesis in luteal phase) [27]. Its inducing cell death (tumoricidal) action is established in ovarian, cervical, breast, gastric, colon, lung cancer cells via oxidative stress related induction of pro-apoptotic caspase $3,8,9$ hydroxy oxidase (a reduction in BCL-2, BCL-XL and Bid protein, increased Bad gene expression and induced DNA fragmentation $[28,29]$. However, it showed side effects of nausea, headache, rashes. The herb is approved by German Commission E with warnings of chaste tree fruit with irregularities of manustrual cycle, mastodynia under the doses of 30-40 mg per day in aqueous-alcoholic extracts.

\section{Dragons Blood (Calamus Draco)}

It is commonly known with fruits of dragons blood used along with illicit marijuana use. It is restricted in human use. Its wider use is in coloring industries, varnishes, lacquers and plasters, incense. It needs investigations if useful in human use.

\section{Psoralea Fruit (Psoralea Corylifolia)}

It is psoralea fruit with side effects of internal burning, allergic responses, phototoxicity. These adverse effects made its use restricted by UK Committee on Safety of Medicines (CSM) due to predisposition of adverse allergic reactions [30].

\section{Cubeb Berry (Piper Cubeba)}

It is traditional black pepper is used as spice known with antimicrobial, antioxidant, and insecticidal properties as food preservative. Traditionally cubeb berry is used in treatment of gonorrhea, bronchitis, hepatitis, inflammation, pain, oxidative stress induced biological injury. Still its use is limited as kitchen spice and research is needed for its anticancer properties if any.

\section{Mace (Myristica Fragans)}

It is cooking herb from plant nutmeg and mainly used in bakery. Its use in low dose of less than $300 \mathrm{mg} / \mathrm{kg}$ day is recommended with no serious side effects. However, overdose of 5 grams/day showed nutmeg side effects including psychological hallucinations, delusions, dizziness, psychosis and sedation, and coma. Its action is not much known but predicted as proliferation inhibition in leukemia, lung and colon cancer induced by myristicin or dihydroguaiaretic acid ingredients [31]. Other actions of anti-inflammatory, antimicrobial, liver detoxification, cholesterol lowering effects are known as potential benefits of nutmeg.

\section{Senna Leaf (Senna Alexandria)}

It is APHA-BSH class 2 herb commonly used in intestinal obstruction, hemorrhoids, to promote bowel movement, relief constipation. Its main ingradients are sennosides as nontoxic but other constituents are known as intestinal irritants. So, its use is warranted with caution among individuals with intestinal disorders, liver damage. It was reported to interfere with absorption of therapeutic drugs and allergic response in susceptible individuals [32]. German Commission $\mathrm{E}$ brought its chronic use in daylight with electrolyte imbalance, potassium deficiency, albuminuria, hematuria, cardiovascular and muscle weakness. For these reasons, further research is required to elucidate plant constituents responsible for anti-cancer effects of Senna.

\section{White Sage (Salvia Apiana)}

It is AHPA-BSH class $2 b$ herb widely known as fodd preservative, flavoring medicinal agent to treat headache, pain, indigestion, heart disease, influenza. It has ingradients of polyphenolics, rosamarinic acid, camphor and carnasol with medicinal properties as anti-inflammatory, antioxidant, antimalarial, antibacterial, and antifungal effects [33]. The administration of essential oil of white sage showed beneficial effects on memory, cognitive function, mood and alertness [34], Alzheimer disease [35]. However, it showed toxicity primarily associated with induced hypoglycemia, tachycardia, convulsions, muscle cramps, respiratory disorders [36]. German Commission E approved its internal use for dyspeptic symptoms and excessive perspiration and external use in oral inflammations with recommended dry leaf intake: $1-3 \mathrm{~g}$ three times daily or fluid extract $1: 1(\mathrm{gm} / \mathrm{ml}) 1-3 \mathrm{ml}$, three times daily. Due to reported adverse side effects, its use is limited not more than 4-6 grams daily despite of long known benefits of senna leaves [37].

\section{Rosemary Leaf (Rosmarinus Oficinalis)}

It is APHA-BSH class 2b/emmenagogue herbs known for cooking applications and treating mucle pain, arteriosclerosis, alopacea and infections. It has phenolic compound camosol reported as lehal against acute lymphoblastic leukemia, colon cancer [38], breast cancer [39]. German Commission $\mathrm{E}$ approved its limited internal use for dyspeptic complaints in dose of 4-6 gm cut leaves and external use as 
powder or dry extract for rheumatic diseases and circulatory diseases.

\section{Eucalyptus Leaf (Eucalyptus Globules)}

It is APHA-BSH class 2 herb and it is contraindicated with liver, gastrointestinal tract, bile duct disease reported by German commission E. It is known for its internal use to induce convulsions, nausea, vomiting, blood pressure drop. However, it is reported as potent therapy of cold, headache, infections, inflammation, arthritis, pain and bacterial infections [40, 41]. Less data is available and more investigations are needed to establish its value in cancer prevention.

\section{Feverfew (Tanacetum Pathenium)}

It is well known herb with anti-cancer properties and prophylaxis in migraine. It contains parthenolide as active ingredient. Its action is reported as inducing prostaglandin synthesis to act as anti-migraine, anti-thrombotic and anti-inflammatory agents [42]. However, it showed allergic reaction that restricts its use in susceptible individuals for human use.

\section{Red sandalwood (Pterocarpus Santalinus)}

It is APHA-BSH class 1 herb for potent use in diabetes, wound healing and dermatitis. The action of sandalwood is less known but well reported in skin papilloma prevention [43].

\section{Yellow Dock Root (Rumex Crispus)}

It is APHA-BSH class 2 herb rich in oxalate contents and used in chronic skin conditions, psoriasis, jaundice, constipation, anemia. It shows allergic reactions and side effects of hypocalcaemia, metabolic acidosis, tremors, ataxia etc. [44]. These adverse effects restrict its use in kidney complications such as renal stones.

\section{White Cherry Bark (Prunus Serotina)}

It is less known plant product with proven anticancer properties such as antiproliferative action via downregulation of cyclin D1 expression/apoptotic effects in colorectal cancer [45]. However, it contains trace levels of cyanide ions less than $0.5 \%$ that makes it restricted in pregnancy and persons with liver or kidney disease. It needs more research for its safety in internal use.

\section{Bushy Knotweed Rhizome (Polygonum Cuspidatum)}

It is known plant with noxious, invasive weed with potentials of anti-ischemic reperfusion injury, cholesterol lowering, antibacterial, anti-viral, esterogenic and blastoma cell cytotoxic anti-cancer properties [46]. Unconfirmed report showed the presence of 3,4' dimethoxy-5hydroxystilbene in this plant which has action of methylation/acid hydrolysis of resveratrol-3 O glucoside to induce apoptosis in leukemia [47]. Resveratrol is known to induce proapoptotic /antiproliferative action by inhibiting nuclear factor NF-kappa B, COX-2 in arresting mammary carcinogenesis [48].

\section{Birch Leaf (Betula Alba)}

It is kind of tea known to flush kidneys used in 5-10 grams in boiled water in routine. Not much known for the possible anticancer properties. Its allergic response also restricts its use in human individuals with known allergies.

\section{Elecampane Root (Inula Helenium)}

It is known herb for the use in cold, flu, pain, skin infections, parasite infections. It is rich in inulin and helenin components with potentials of anticancer effects. However, it contains chemical alantolactone with allergic response that restricts its use even in skin dermatitis [49].

\section{Ginger (Zinggiber Officinale)}

It is regular kitchen spice routinely used in cooking. Its properties of anti-platelet aggregation, anti-inflammatory, analgesic, anti-microbial, anti-worm, anti-oxidant, hyperlipidemic, anti-arthritic and hypoglycemic effects are well documented [50]. In Indian traditional Ayurvedic system, it is known for having anti-nausea, vomiting effects in pregnancy, arthritis. However, its use in cancer is very less known including its inhibitory effect on angiogenesis, inducing effect on apoptosis in experimental animals $[51,52]$. In human use, it is approved by German Commission $\mathrm{E}$ in the amount of 5-10 grams daily [53], APHA-BSH in the amount of 4-6 grams/day.

\section{Turkey Rhubarb (Rhenum Palmatum)}

It is APHA-BSH class 2 herb with high oxalate content with contraindications in people with renal stones or intestinal obstruction. It has active anticancer ingradient known as hydroxyanthraquinones and anthraquinone glycosides with anti-proliferative/anti-mutagenic activity [54]. However, high oxalate content restricts its long time use due to oxalate binding property with metals. Very less is known for its anticancer safe use in humans.

\section{Cinnamon (Cinnamomum Cassia)}

It is APHA-BSH class 2 herb with known anticancer, anti-microbial, anti-fungal and anti-diabetic properties [55]. However, it also showed inducing hypertension, skin allergy, and cathartic in diabetes that makes its use restricted in sensitive individuals. Both German commission E and APHABSH have recommended limited use 2-4 grams/day as bark for appetite loss, dyspepsia, flatulence.

\section{Kava Kava (Piper Methysticum)}

It is herb with active gradient of kavalactones kavain, dihydrokavain, methysticin, dihydromethysticin, yangonin, desmethoxyyangonin), with known to cause psychoactivity and liver toxicity effects. The pharmacological effects are muscle relxation, anesthetic, anticonvulsive, anxiolysis, with possible therapy of ovarian cancer, leukemia. However, skin rashes and liver toxicity due to piperidine alkaloid restrict its use in humans by CDC.

\section{Arjun (Terminalia Arjuna)}

It is herb routinely used for angina, hypertension, ecchymosis, gonorrhea, coronary heart disease, hypercholesterolemia. 


\section{Babul Chalk Bark (Acacia Arabica)}

Acacia Bark also known as Wattle Bark, is collected from wild or cultivated trees, seven years old or more. Acacia Bark contains from $24-42 \%$ of the tannin gallic acid. Medicinally, Acacia Bark is employed as a substitute for Oak Bark. Acacia Bark has special use in diarrhea, mainly in the form of a decoction, the British Pharmacopia preparation being 6 parts in 100 administered in doses of $1 / 2$ to 2 fluid ounces. The decoction also is used as an astringent gargle, lotion, or injection in doses of $1 / 2$ to 1 fluid ounces. The use of both gum and bark for industrial purposes is much larger than their use in medicine.

\section{Bhumi Amalaki (Phyllanthus Niruri)}

It is traditional herb in use for viral hepatitis, chronic liver disorders, jaundice, constipation, dyspepsia, anorexia, with known effect of liver detoxification. Its anticancer properties not reported at all.

\section{Goldenseal (Hydrastis Canadensis)}

Typically known as Goldenseal herb with known effects like rifampin and clarithromycin. The action was reported as phytochemical mediated modulation of p-glycoprotein [56].

These said herbs display anticancer effects along with other therapeutic actions because of whole herbs without concentrated active ingredient(s) used. The therapeutic action is measured and reported as $\mathrm{LC}_{50}$ dose in normal experimental homogenous cancer cell lines in culture to determine the effective maximum dose tolerance after exposure to herbal extracts or whole concentrates. Although the knowledge of herbal anticancer effect is very poorly known but sufficient data is available to design herbal anticancer formula. For simplicity, a gross and tentative list of herbs is presented shows relative strengths of herbs as anticancer supplements. The molecular mode of herbal biochemical action is far from the present discussion on how these herbs could be used and for how long. The following discussion is a window or glimpse to explore the possibility of anticancer herbal therapy.

\section{ANTICANCER PROPERTIES OF HERBS:}

A tentative list of herbs is presented with experimental values of anticancer screening (lethal value LC50 in $\mathrm{mg} / \mathrm{mL}$ ) in Table $\mathbf{1}$.

\section{HERBS AS ANTICANCER IN HUMAN USE:}

Herbs have demonstrated their effect in isolated cultured cells or in patient use mainly by Chinese or Ayurvedic Indian traditional methods. To implement herbs in human use, lethal dose of herbs in animals $\left(\mathrm{LC}_{50}\right)$ have been reported but unconfirmed. To mention here a few as listed in Table $\mathbf{2}$, the following limited number of herbs and their different parts of plant indicate their approval by FDA and CDC with safe use in humans. The efficacy of these herbs still remains a stigma if patient's improved condition is related with herbal efficacy without double blind placebo based clinical trials. However

Table 1. These Cited Herbs have Potential as Anticancer and Tested in Human use but not Approved or with Safety Warning [See the Reference 57]. The List is a Comparative Account of Safe Use in Human as Anticancer Effective Potency Shown in Brackets

\begin{abstract}
Strong anticancer herbs: Alkanet root (0.138); Kochea seed (0.147); Blood root (0.04); Bakuchi seed (0.102); Chapparral (0.124); Cubeb berry(0.263); Dragon blood (0.242); Sweet myrrh(0.158); male fern rhizome (0.232); Dragon blood(0.242); Psoralea fruit(0.243); Senna leaf (0.275); Rosemary (0.299); Black papper (0.495); Blue cohosh root(0.218); Babul bark (0.492); Buckthrone bark (0.107); Bhumy amalaki ( 0.497); Butternut bark (0.506); Eucalyptus leaf (0.305); Feverfew (0.307); Osho root (0.509); Sage (0.519); Red sandalwood (0.326); Yellow dock root (0348); Wild cherry bark (0.360); Berch leaf (0.365); Kava kava (0.491); Elecampane root (0.447); Turkey rhubarb (0.466); Cinnamon (0.479); Green tea (0.507).
\end{abstract}

Less known herbs or one time evidence of their anticancer properties are listed below as tentative list [57]. It is a handout list to readers interested in to become aware of possible less known herbs either tested one time in preclinical Chinese or Ayurvedic use or likely to be the prospective anticancer herbal candidate.

Potential anticancer herbs: Yam Root, abalone shell, tertraphylla root, ailanthus bark, mimosa bark, alfafa leaf and seeds, alum, angelica, snise seed, Ash bark, Ashwanda root, Astralgus root, Bamboo leaf, Barley grass, Bee pollen, Bilberry fruit, Black Haw, Blue Green Algae, Blue Verian, Borage, Buddleia Flower Bud, Bugleweed, Burdock root, Cardamom, Carob Powder, Carpesium fruit, Cassia seed, Catnip, Chamomile, Chervil, Chickory root, Chickweed, Chinese Holly leaf, Chlorella, Cilantro, Cleavers, Clemetis root, Club moss, Codonopois root, Coix seed, Coltsfoot, Comfry leaf, Corn silk, Cortyceps, Couch grass, Cranberry powder, Dandelion root, Dill seed, Dittany root bark, Dog grass root, Don Quai root, Dulse, Echinechea, Eleuthro root, Erend herb, Eucomnia, Eyebright, False unicorn root, Fennel seed, Fenugreek, Flax seed, Fo ti, Forsythia Fruit, Foxnut barley, Fringe bark tree, Fumitory herb, Gential root, Ginseng, Glaborous greenbrier rhizome, Glehnia, Gloryvine stem, Goats Rue, Goldenseal, Green Clay, Guduchi root powder, Gypsum, Hawthorne berry, Helichrysum flowers, Hibiscus, Homalomena rhizome, Honeysuckle vine, Horsetail, Houttuynia cordata, Hydrangea root, Hylocerus flower, Hyssop, Isatis leaf, Jasmine flower, Kadsura stem, Kelp, Knotweed grass, Kola nut, Kombu, Kudzu root, Kukicha Twig, Laminaria(Kelp), Lemon, Lobelia, Lotis leaf or root, Lungwort, Lycii berries, Lycium bark, Lycopodium japonicum vine, Marshmallow root, Melilot herb, Mica-Schist, Milk Thistle seed, Mother-Of-Pearl, Motherwort, MSM, Mugwort, Muirapuama, Mettle root, Noni juice, Onion powder, Orange, Pagoda tree fruit, Paprika, Parsley leaf or root, Passion flower, Peppermint, Perilla leaf or root, Periwinkle, Pigeon pea root, Pivet fruit, Plantain leaf, Pleurisy root, Poke root, Poppy seed, Psylliam seed, Puff-ball/Lasiophaera, Purnarnava herb, Pyrrosia leaf, Red clover, Reed rhizome, Rehmannia root, Rooibos tea, Rosehips, Safflower threads, Saffron, Scrophularia root, Scutellaria barbata herb, Self heal, Shank pushpin herb, Shephards purse, Skull cap, Slippery Elm, Soloman seal, Spearmint, Speranskia herb, Spilanthes, Spirulina, Stone lotus seed, Swalloeort root, Tonka bean, Tribulus, Uncaria vina with hooks, Vanilla root, Vasak leaves powder, Vasma Rochna leaves, Watercress, Wheat grass, White Oak bark, White Peony root, White pine powder, Woolly grass rhizome, Yellow mustard seed, Yohimbe bark, Yucca root, Zedoary rhizome. 
Table 2. Handbook of Herbs is Proposed Showing Potency of Action in Decreasing Order. The Therapeutic Potency of Selected Herbs $\left(\mathrm{LC}_{50}\right.$ Values in $\left.\mathrm{mg} / \mathrm{mL}\right)$ Indicates the Anticancer Potential of Herbs in Human use as Confirmed for Cancer Therapeutic Use. The Following List Highlights the Possible Use of Different Parts of Herb Plants in Developing Herbiceuticals and Anticancer Formula

Anticancer herbs: Wild Yam(0.19); Teasel root(0.42); Balm of Gilead bud (0.78); Frankincence (0.081); Dichroa root(0.137); Kanta kari(0.157); Garcinia fruit(0.235); Mace(0.271), Mhyrr gum(0.283); White sage (0.299); Vitex powder (0.302); Bushy Knotweed rhizome (0.361), Ginger root (0.447), Nutmeg $(0.447)$

Medicinal plants or their parts are shown below as known with possible anticancer properties

Bark: Buckthrone, Chaparral, Sandalwood, Wild cherry, Babul, Butternut bark, Cramp, White billow, Catuaba, Cascara sagrada, Paul D’ Arko, Wood betany, Pygeum,

Seeds: Bakuchi, Kochia, Cinnamon, Black papper, White papper corn, Black walnut hull, Annatto, Habernaro, Celery, Corriander, Guarana, Cumin, Caraway, Lychee pit, California poppy

Roots: Yellow turmeric, Blood root, Alkanet, Yellowdock, Elecampane, Kava kava, Osho, Redroot, Buplerum, Terragon, Green mosaia, Licorice root, Lovage root, Barberry root, Witch hazel root, Lindera, Blue cohosh, Cranebill, Red henna, Bay berry, Gravel root, Butches broom, Pulsatilla, Blackberry, Galangal, Birch bark root, Rhodiola, costus, Aster, Orris, Sophora, Yarrow root, Calamus, Beet

Leaf: Senna, Rosemary, Eucalyptus, Feverfew, Damiana leaf, Birch, Bhumi amalaki, Green tea, Gymnema, Sage, Pipsissewa, Vidanga, Boldo, Bay leaf, Bilberry leaf, Nageshkar leaf, Damiana, Ashoka, Neem leaf, Papaya leaf, Raspberry, Stevia, Biota, Linden, Patchouili, Strawberry,olive, Buchu, Lemon grass, Blue violet, Lemon verbena, Yerba mate, Black walnut, Artemisia,

Whole herb: Dragon blood, Turkey rhubarb, Cynomorium songaricum, Arjun, Horse chestnut, Black henna, Uva ursi, Rabdosia rubescens, Usnea, Brahmi, Sasparilla, Spikenard, Wintergreen, Epidedium, Soap wort, Blessed thistle, Lady's mantle, Pennyroyal, Bladderwrack, Oatstraw, Centipeda, Thyme, Cat claw, Boneset, Iceland moss, Meadow sweet, Savory winter, Wormwood, Mistle toe, Golden rod, Horehound, Luffa sponge, Elsholtzia, Siegesbeckia, Celandine, Basil, Gotu kola

Rhizome: Dryopteris fern, Sweet myrrh, Usnea, Brahmi herb, Maiden hair, Coral calcium, Drynaria, Curculigo

Fruit: Psoralea, Pipli, Karela, Copal resin, Oregon grape, Conchord grape juice, Terminalia,

Berry: Cubeb, Schisandra, Cidar, Saw palmetto, Sumar,

Powder: Superior gun powder, Pomegranate husk, Sambhar, Haritaki fruit powder, Pashanbheda herb powder, Garlic powder, Kutaj bark powder, Satavari, Kachnar, Bringraj, Allspice berry powder, Musta root powder, Bilwa fruit powder, Cayeen, Lavan bhaskar, Maca powder, Psyllium husk, Lemon balm,

Flower: Lavender, Calendula, Rose petals, Pyrite, Clove, Agmoni, Oregano, Malva flower, Heather

in lesser quantities the whole herbs without isolation and extraction of active components display their harmless side effects.

\section{BIOMARKERS IN EVALUATION OF HERBS AS ANTICANCER}

In human body, metabolism is a cycle of biochemical reactions catalyzed by enzyme proteins where these enzymes act very specifically as regulating the biochemical reactions in presence of cofactors and coenzymes as shown below with their anticancer effects. These enzyme serve as biomarkers of the herbal effecting the tissue.

\section{Pyruvate Kinase, Cytochrome Oxidase Enzymes}

In the presence of oxygen, the mitochondrial complex I and IV subunits function together as dependent on each other. Their catalytic binding with active herb component (nutraceutical like riboflavin, FMN, FAD) provides the measure of cancer cell status. The flavins enhance the oxygen utilization by cytochrome oxidase and keep low the aerobic glucose utilization to generate ATP (substrate level phosphorylation). The enhanced $\mathrm{V}_{\max }$ and reduced $\mathrm{K}_{\mathrm{m}}$ value for reduction of mitochondrial complexes I and IV are indicators of mitochondrial function in cells. In cancer cells, in presence of oxygen, cytochrome oxidase competes with anerobic glucose utilization) and substrate level phosphorylation to generate ATP.

\section{Lactate Dehydrogenase Enzyme}

In cancer cells, high LDH enzyme levels (indicator of anaerobic metabolism) and reduced ratio of equivalents NADH/FADH (during acetyl-CoA utilization by TCA cycle) indicate the low availability of NADH to electron transport chain in making ATP. Morin, an anticancer inhibits LDH-V M4.Examples: Ubiquinones.

- Anaerobic cytosolic carboxylation (TCA cycle status and ETS enzyme battery): Inhibition of aconitase, isocitrate lyase, malate synthase. Example: Withania somnifera.

- High mitogen/stress pathway kinase activity. Example: Morin [58].

- Tropoisomerase enzyme inhibition. Example: Frankincense (Boswellia carteri) [59].

- p-glycoprotein ATP efflux Example: Flavanoids [60].

- Arrested G2/M, downregulation of NF-kappa B, Akt, cyclin D, c-myc to lead PARP cleavage and DNA fragmentation. Examples: Vitex, wild yam (Dioscorea villosa) [61].

- Antiproliferation and induced apoptosis (Caspase-3/8/9) and PARP cleavage). Example: Garcinia cambogia (garcina fruit), Mace [62].

- Blocked leukotriene/5-lipoxygenase pathway. Example: Hunteria zeylanica bark [63, 64]. 
- Garcinia cambogia (garcina fruit) inhibits nuclear histone acetyltransferase p300 and PCAF, as indicator of proapoptosis (beginning or initiation) after cancer cells indicate cell proliferation, migration, cell adhesion and viability. Other biomarkers are inhibited MAP kinase, ER kinase, P13K/Akt, membrane adhesion kinase with activated cytochrome $\mathrm{C}$ release and PARP-1 cleavage [65].

- Oxidative stress induced pro-apoptosis: Reduced BCL-2, Bcl-XL and Bid protein by Caspase 3,8 9-OH oxidase, enhanced Bad gene expression and induced DNA fragmentation. Example: Vitex [28].

- Downregulation of Cyclin D1 expression/apoptotic effects: Due to reduced proliferation, a pro-apoptosis process initiates to cause cyclin D1 expression. Example: wild cherry bark [66].

- Modulation of p-glycoprotein: Due to phytochemical mediated modulation of $\mathrm{p}$-glycoprotein process initiates anticancer behavior of herbs. Example: goldenseal and Kava kava [67].

- Expression of gene: Downregulated gene expression of silbinin synthase enzyme causes the activation of nerves and brain activity with enhanced immunity. Example: JIVA $^{\mathrm{TM}}[68]$.

\section{BIOCHEMISTRY OF ANTICANCER HERB ACTIVE COMPONENTS IN HUMAN USE APPROVED BY CDC AND REGULATED BY FDA}

The herbs are rich in different metabolites plying role in active intermediary metabolism and these are needed in body in a minimum amount daily so called recommended daily allowances (RDA) through diets or herbal supplements. A number of herbal active ingredients are listed below in Table 3 and some of them identified as shown in Fig. (1) specifically abundant in herbs as shown in Table 4.

Table 3. Active Metabolites in Herbs Needed in the Human Body (RDA) and Participating in Biochemical Reactions. These Compounds are Used in Making Anticancer Herbal Formula

\footnotetext{
Ubiquinone and derivatives (RDA: $300 \mathrm{mg} / \mathrm{day} ; 3 \% \mathrm{wt}$ fraction):

Coenzyme Q and derivatives(RDA $300 \mathrm{mg} /$ day; 3\% wt fraction):

Riboflavin and derivatives (RDA $300 \mathrm{mg}$ /day; therapeutic dose $1000 \mathrm{mg} ; 3 \%$ wt fraction): Riboflavin
}

2',3,4',5,7- Pentahydoxyflavone (therapeutic dose $1000 \mathrm{mg}$ )

Polyphenolic Flavonoid and derivatives(RDA $800 \mathrm{mg} /$ day; therapeutic dose $2000 \mathrm{mg}$; $9 \%$ wt fraction): 2-3 dimethoxy-5-methyl-1,4 benzoquinone (therapeutic dose $2000 \mathrm{mg} /$ day; $31 \%$ wt fraction)

Alkaline compounds (RDA $750 \mathrm{mg} /$ day; $18 \%$ wt fraction): Sodium or potassium bicarbonates

Antiproliferative bioactive herbs (RDA $200 \mathrm{mg} / \mathrm{ml} ; 5 \% \mathrm{wt}$ fraction): Speranskia or goldenseal herb powder (therapeutic dose $2000 \mathrm{mg}$ ); Aloe vera, Chlorella

Balm of Gilead buds, Wheat grass, Red sandalwood, Rosemary (therapeutic dose 1500 mg/day; $58 \%$ wt fraction) with Myrrh gum (therapeutic dose 500 $\mathrm{mg} /$ day); Black walnut (therapeutic dose $2000 \mathrm{mg} /$ day, $17 \%$ wt fraction) to inhibit LDH.

FMN, FAD, 5-amino-6-(5'phosphoribitylamino) uracil, 6,7 Dimetyl-8-(1D-ribityl)lumazine, ribitol, 5,6-dimethylbenzimidazole (therapeutic dose 300 $\mathrm{mg} / \mathrm{day}$ of each<smiles>Cc1cc2nc3c(=O)[nH]c(=O)nc-3n(C[C@H](O)[C@H](O)[C@H](O)CO)c2cc1C</smiles><smiles>O=c1c(O)c(-c2ccc(O)cc2O)oc2cc(O)cc(O)c12</smiles>

2,4,5,7-pentahydroxyflavone

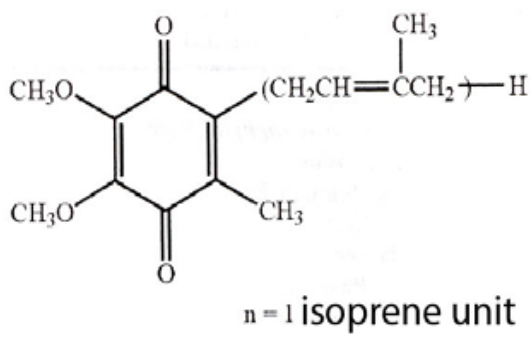

isoprene unit of ubiquinone

Fig. (1). Chemical structure of bioactive components abundant in herbs, roots and medicinal plants. They are used as nutraceuticals with possibility of anticancer component in design of nutraceutical therapeutic formula. 
Table 4. Different Active Chemical Compounds (Herbiceuticals) or Ingradients are Shown in Herbs with Known Anticancer Effects

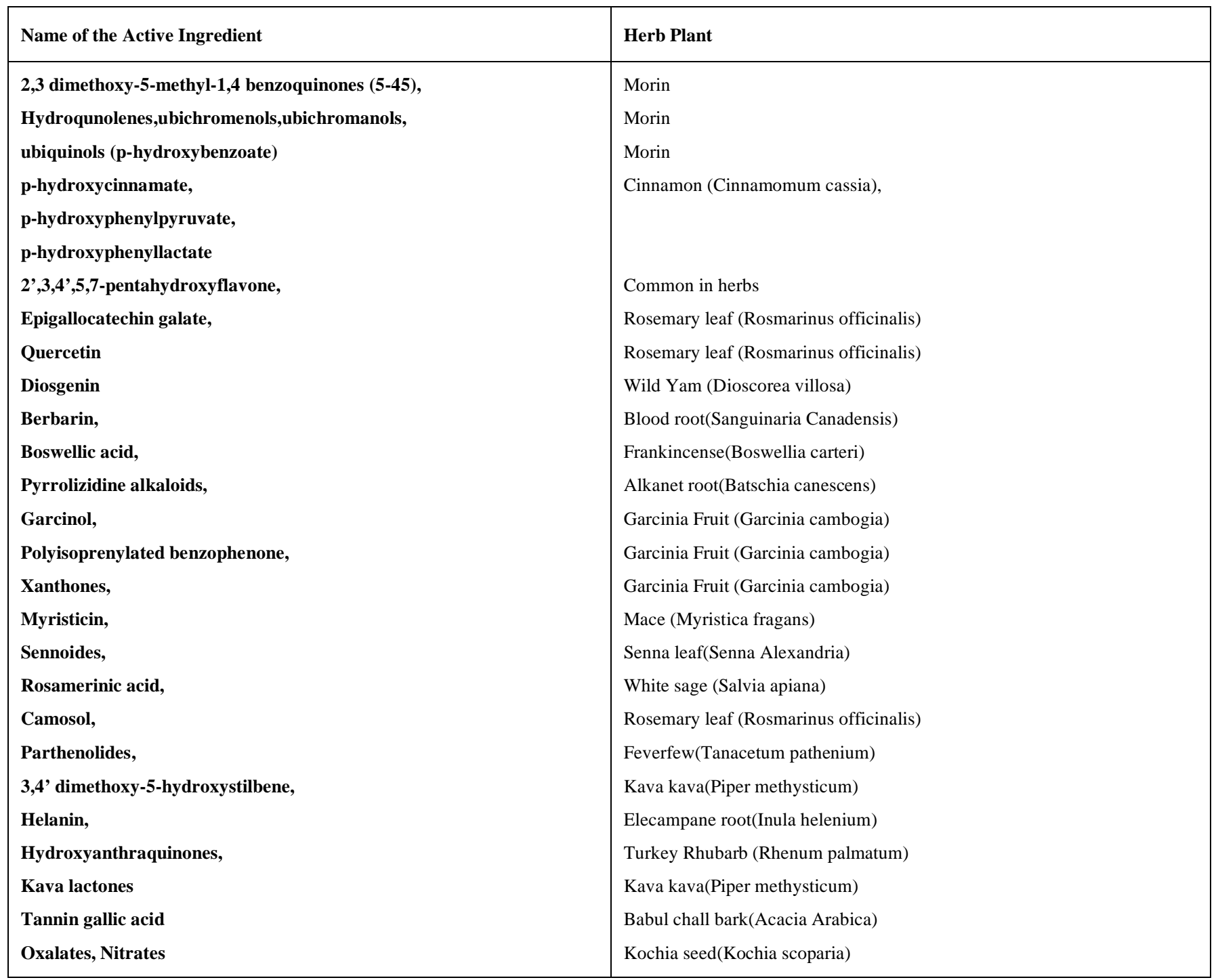

\section{MECHANISM OF TUMOR TREATMENT BY HERBS}

The author proposes the concepts of biochemical intracellular changes in cancer cells in step-by step leading to arrested growth or cancer cell killing as shown in Fig. (2). A scheme is drawn showing macro effects of herbs on tumor size down to cellular metabolic state leading to the inhibited subphysiological condition of tumor cellular survival. Major subphysiological changes are metabolic integrity loss, hypoxia and oxygen starvation of tumor cells with more burden of rapid growth (proliferation). The herbal therapeutic effect presumably is competitive inhibition of available energy molecules to fast growing tumor cells and make them further poor in energy and oxygen starved till the tumor cells become dysfunctional.

The following is a biochemical account of herbal induced tumor cell killing:

- The effect of herbs is measured by tumor volume, animal weight, tumor size shrinkage, inhibited cell growth, \% loss of cell viability, inhibited biomarkers (enzymes),
- What herbs do on host cells? The aerobic glucose oxidation in normal cells leads to enhanced mitochondrial oxidative phosphorylation in presence of oxygen. High concentration of $\mathrm{CO}_{2}$ suffocates the normal cells and anerobic glucose oxidation result with halt in mitochondrial energy. So, it does not favor the host normal cells for long time.

- Cancer cells demonstrate high glucose consumption, high glycolytic rate, rapid cell proliferation, lactic acid accumulation, extracellular acidic low $\mathrm{pH}$, low glucose available, oxygen deprivation or hypoxia. Overall, it resists the chemotherapeutic action.

\section{Concept 1}

Tumor cells starve due to blocked anerobic glucose utility by herbal active component(s): The glucose utility block augments the aerobic energy metabolism in host. The block leads the lactate dehydrogenase inhibition and suppressed cytosolic TCA cycle (2,3 dimethoxy-5-methyl-1,4-benzoquinone (DMBQ) in coenzyme Q10. The blocked glycolysis 
[n Cancer Elevated Glycolysis (Anaerobic glucose) is normalized by Mitochondrial Oxidation
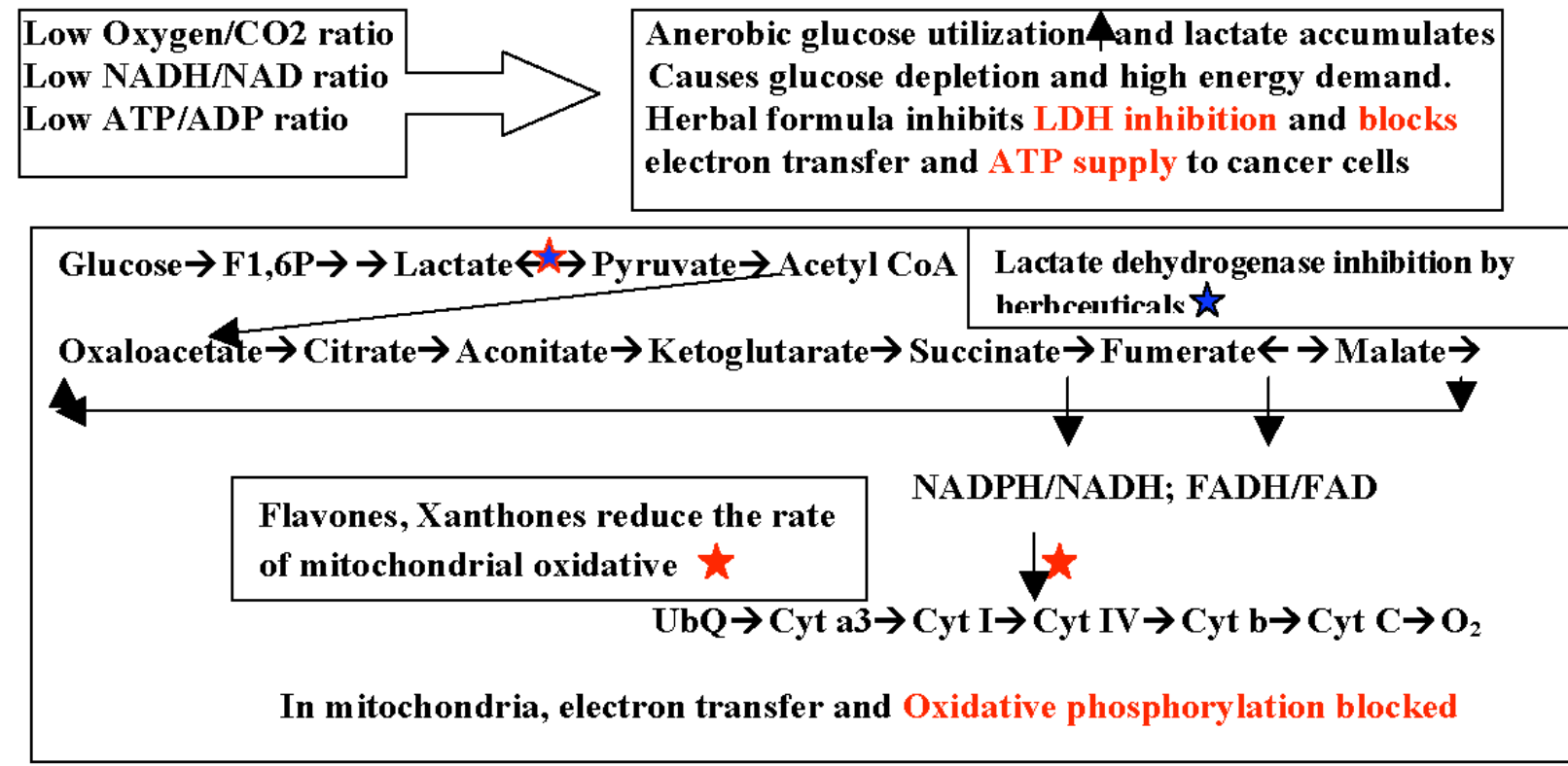

Fig. (2). How herbiceuticals act? A diagramatic sketch of blocked anaerobic glucose utility sites in glucose oxidation and TCA cycle of cancer cell. The metabolic steps are shown for enzymes: fructose 1,6-bisphosphatase, acetate-CoA ligase, malate synthase, isocitrate lyase, aconitase, phosphoenol carboxylase/carboxykinase, glycolate oxidase, phosphoglycolate phosphatase, glycolaldehyde dehydrogenase, pyruvate carboxylase, citrate lyase, ferridoxin oxidoreductase, 2,3-diphosphoglycerate mutase, propionyl CoA carboxylase, malic enzyme and acetyl CoA carboxylase. The mitochondrial respiration shows metabolic steps of oxidative phosphorylation and electron transport chain.

also favors mitochondrial oxidative function through complex I-IV (example riboflavin, FAD, FMN derivatives)

\section{Concept 2}

Oxygen depletion and hypoxia in tumor: High oxygen is not good for tumor cells. High oxygen in tumor cells causes high mitochondrial respiration (where oxygen is a substrate for mitochondrial complex IV) and high alkalinity.

\section{Concept 3}

Inhibition of lactate dehydrogenase (LDH-V M4): The LDH plays active role in development of malignancy as enzyme $\mathrm{LDH}$ generates product NAD+ and 2 pyruvate molecules from one glucose. Immediately NAD+ is consumed as cofactor of glyceraldehydes-3-phosphate dehydrogenase to push more ATP more production through anaerobic metabolism catalyzed by phosphoglycerate/ pyruvate kinase. While pyruvate molecule gets into acetylCoA by pyruvate dehydrogenase in aerobic metabolism.

\section{PHARMACEUTICAL APPROACH OF HERBICEU- TICAL FORMULA WITH ANTICANCER PROPER- TIES}

The neutraceutical composition is widely advocated in cancer therapy based on combination of vitamins, salts, roots and herbs prepared in palatable pharmaceutical carrier as neutraceutical composition initially proposed by Mazzio et al. [57]. Alternatively herbiceuticals may be used more efficiently if using in combination with more $\%$ of flavones in the mixture as proposed in this paper.

\section{Anticancer Herbiceutical Formula}

A simple plan of anticancer formula is suggested for herbiceutical mixture including active biochemicals, herbs, roots in suitable carrier for cancer therapeutics:

\section{Group 1: Herb Group: $(60-90 \%$ w/w $)$}

Wild yam root (Dioscorea villosa), teasel root (Dipsacus asper), balm of gilead bud (Populus balsamifera), bakuchi seed (Cymopsis psoralidoides), dichroa root (Dichroa febrifuga), kochia seed (Kochia scoparia), kantakari (Solanum xanthocarpum), bushy knotweed rhizome (Polugonum Cuspidatum), arjun (Terminalia arjuna), babul chall bark (Acacia Arabica), Sweet Myrrh (Opopanax) and bhumy amalaki (Phyllanthus niruri), Garcinia fruit (Garcinia Cambogia), Vitex (Vitex agnus-castus), Dragons Blood (Calamus draco), Mace (Myristica fragans), White sage (Salvia apian), red sandal wood (Pterocarpus santalinu)

\section{Group 2: Ubiquinone with Precursor: (50-90\% w/w)}

2,3 dimethoxy-5-methyl-1,4 benzoquinones (5-45), hydroqunolenes, ubichromenols, ubichromanols and ubiquinols in form of p-hydroxybenzoate, p-hydroxycinnamate, p-hydroxyphenylpyruvate, p-hydroxyphenyllactate.

\section{Group 3: Mitochondrial Respiration Suppressors:} $(70-90 \%$ w/w)

Ribitol, riboflavin, flavin adenine dinucleotide, 5-amino6-(5'-phosphoribitylamino)uracil, 6,7 -Dimethyl-8-(1-Dribityl)-lumazine, 5, 6-dimethylbenzimidazole with multivitamin mixture. 


\section{Group 4: Inhibitor of LDH (60-65\% w/w)}

2',3,4',5,7-pentahydroxyflavone, epigallocatechin galate, quercetin, rosemary (Rosmarinus officinalis), black walnut (Juglans nigra), clove (Syzygium aromaticum), nutmeg (Myristica fragans), licorice root (Glycyrrhiza glabra), coriander (Coriandrum sativum), Cinnamon (Cinnamomum cassia), ginger root (Zingiber officinale), Myrrh gum (Commiphora molmol) and green tea (Camellia sinensis)

\section{Group 5: Alkalinating Agent: (15-20\% w/w)}

Aloe vera(Aloe barbadensis), chlorella (Chorella pyrendoidosa), wheat grass (Triticum aestivum) in solution of sodium or potassium carbonate

\section{Group 6: Antiproliferative Herbs: $(5-10 \%$ w/w)}

Speranskia herb (Speranskia tuberculata) and Goldenseal (Hydrastis canadensis).

Carrier of different herbiceutical components: The said herbal mixture in water, saline, starch, sugar, gel, lipids, waxes, glycerol, solvents, oils, liquids, proteins, glycols, electrolyte solutions, alcohols, fillers, binders, emulsifiers, preservatives, buffers, colorants, emollients, sweeteners, surfactants, additives and solvents may be used as: solid, liquid, powder, paste, gel, tablet, foam, pack, aerosol, solvent, diluent, capsule, pill, liposome, syrup, solution, suppository, emulsion, suspension, biodelivery agents. The nutraceutical mixture may be delivered through oral, injectable or external administration for treatment of cancer of: skin, breast, breast, colon, kidney, bone, blood, lymph, stomach, gastrointestinal, ovary, prostate, liver, lung, head and neck, adrenal, brain, bronchial, hypothalamus, parathyroid, thyroid, pancreas, pituitary, sinus, endometrium, bile duct, leukemia, AIDS, astrocytoma, glioma, lymphoma.

Controversial status: Several bioactive compounds such as CoQ2,4,6 and CoQ10; and herbs such as knotwood rhizome, elecampane root, Turkey rhubarb are less understood and their anticancer properties remain controversial.

Recently, the safe use of nutraceuticals and nutraceutical supplementation formula was reviewed by author with major focus on preclinical and clinical evidences and role of regulatory federal governments on bioactive foods, herbs and use of nutraceuticals [69].

\section{FUTURE PROSPECTS OF HERBS AS POTENTIAL ANTICANCER SUPPLEMENTS IN CANCER PREVENTION}

With slow progress and increasing awareness of herbal benefits, common person is getting confidence to use them safely and in risk-free manner. Research investigations are also contributing eye-catching evidences of newly introduced or less known potential herbs having anti-cancer effects and their safe use for humans. Major issues are lack of valid co-relations between herbal ingredients and their structural relationship with anticancer biological activity in terms of measurement of intracellular biomarkers. The growing hypes of industries and herbal economics put several questions behind before any herbal side effect or ill effects become apparent. To avoid these controversies, in developed countries government and its regulatory agencies are playing significant role to monitor the success and efficacy of new or old herbal products in market. So, it is continuing process of new herbs identified, investigated and researched for their human use under strict supervision and marketing strategies regulated by government policies. With time, herbs may be considered as therapeutic herbs and effective preventive supplements in cancer prevention. As of today most of the herbs are in use by common person based on herbal effects as word of mouth from friends, relatives etc.

It needs attention sooner before they become common hazard going unnoticed. Government marketing policies need to be stringent to make available herbs in approved limits of concentration under supervision of herbal pharmacy personnel as it is described in this paper. Hopefully some kind of policy will be introduced in near future that will minimize the chances of herbal over dosage or over intake unrestricted.

\section{CONCLUSION}

In present paper, herbs are surveyed to demonstrate their benefits in human health and possible use as anti-cancer supplements. The pharmacological action and biochemical mechanisms of herbs are highlighted for their possible effects on tissue and anticancer action. A possible herbal anticancer composition is proposed for make effective anticancer herbal formula. The focus of paper is a comparison of anticancer strengths of different herbs. The toxic effects of herbal over intake are highlighted to show their side effects. Finally, the aim is to catch the attention of regulatory government bodies on growing unnoticed use of herbs among large population having no knowledge of herbal side effects they are using. So that government or health authorities can remain vigilant in informing public and insurers in time before it is too late.

\section{REFERENCES}

[1] Brazier NC, Levine MA. Brazier Drug-herb interaction among commonly used conventional medicines: a compendium for health care professionals. Am J Ther 2003; 10(3): 163-9.

[2] Butterweck V, Winterhoff $H$, Herkenham M St John's wort, hypericin, and imipramine: a comparative analysis of mRNA levels in brain areas involved in HPA axis control following short-term and long-term administration in normal and stressed rats. Mol Psychiatry 2001; 6(5): 547-64.

[3] McGuffin. American Herbal Products Association's Botanical Safety Hand, CRC Press Inc. 1997 and HerbalGram Copyright American Botanical Council 2000; 48: 42.

[4] Russell L, Hicks GS, Low AK, Shepherd JM, Brown CA. Phytoestrogens: a viable option? Am J Med Sci 2002; 324(4): 185 8.

[5] Fugh-Berman A. Herb-drug interactions Lancet 2000; 355(9198): 134-8.

[6] Shishodia S, Aggarwal BB. Diosgenin inhibits osteoclastogenesis, invasion, and proliferation through the downregulation of Akt, I kappa B kinase activation and NF-kappa B-regulated gene expression. Oncogene 2006; 25(10): 1463-73.

[7] Leger DY, Liagre B, Beneytout JL. Role of MAPKs and NFkappaB in diosgenin-induced megakaryocytic differentiation and subsequent apoptosis in HEL cells. Int J Oncol 2006; 28(1): 201-7.

[8] Syrovets T, Büchele B, Gedig E, Slupsky JR, Simmet T. Acetylboswellic acids are novel catalytic inhibitors of human topoisomerases I and IIalpha. Mol Pharmacol 2000; 58(1): 71-81.

[9] Lichtensteiger CA, Johnston NA, Beasley VR Rhamnus cathartica (buckthorn) hepatocellular toxicity in mice. Toxicol Pathol 1997; 25(5): 449-52. 
[10] Stickel F, Seitz HK, Hahn EG, Schuppan D, Liver toxicity of drugs of plant origin. Z Gastroenterol 2001; 39(3): 225-32, 234-7.

[11] Murata K, Takano F, Fushiya S, Oshima Y. Chemical Constituents from the Roots of Hydrangea chinensis. Nat Prod 1998; 61(6): 729-33.

[12] Bundesinstitut fur Arzneimittel und Medizinproduckte. Complete German Commission E Monographs: The Therapeutic Guide to Herbal Medicines, Lippincott Williams \& Wilkins 1998.

[13] Rankins DL Jr, Smith GS, Hallford DM. Altered metabolic hormones, impaired nitrogen retention, and hepatotoxicosis in lambs fed Kochia scoparia hay. Anim Sci 1991; 67(7): 2932-40.

[14] Gupta RS, Dixit VP. Effects of short term treatment of solasodine on cauda epididymis in dogs. Indian J Exp Biol 2002; 40(2): 169-73.

[15] Haridy FM, El- Garhy MF, Morsy TA Efficacy of Mirazid (Chommiphora molmol) against fasioliasis Egyptian sleep. J Egypt Soc Parasitol 2003; 33(3): 917-24.

[16] Sheir Z, Nasr AA, Massoud A, et al. A safe, effective, herbal antischistosomal therapy derived from myrrh. Am J Trop Med Hyg 2001; 65(6): 700-4.

[17] Rao RB, Hoffman RS. Nicotinic toxicity from tincture of blue cohosh (Caulophyllum thalictroides) used as an abortifacient. Vet Hum Toxicol 2002, 44(4): 221-2.

[18] Finkel RS, Zarlengo KM Blue cohosh and perinatal stroke. N Engl J Med 2004; 15, 351(3): 302-3.

[19] Sharma V, Josheph C, Ghosh S, Agarwal A, Mishra AK, Sen E. Kaempferol induces apoptosis in glioblastoma cells through oxidative stress. Mol Cancer Ther 2007; 6(9): 2544-53.

[20] Zhao W, Kridel S, Thorburn A, et al. Fatty acid synthase: a novel target for antiglioma therapy. Br J Cancer 2006; 9; 95(7): 869-78.

[21] Sebastiani V, Botti C, Di Tondo U, et al. Tissue microarray analysis of FAS, Bcl-2, Bcl-x, ER, PgR, Hsp60, p53 and Her2-neu in breast carcinoma. Anticancer Res 2006; 26(4B): 2983-7.

[22] Jung HA, Su BN, Keller WJ, Mehta RG, Kinghorn AD. Antioxidant xanthones from the pericarp of Garcinia mangostana (Mangosteen). J Agric Food Chem 2006; 22; 54(6): 2077-82.

[23] Zhang HZ, Kasibhatla S, Wang Y, et al. Discovery, characterization and SAR of gambogic acid as a potent apoptosis inducer by a HTS assay. Bioorg Med Chem 2004; 12(2): 309-17.

[24] Balasubramanyam K, Altaf M, Varier RA, et al. Polyisoprenylated benzophenone, garcinol, a natural histone acetyltransferase inhibitor, represses chromatin transcription and alters global gene expression. J Biol Chem 2004; 279(32): 33716-26.

[25] Liao CH, Sang S, Ho CT, Lin JK. Garcinol modulates tyrosine phosphorylation of FAK and subsequently induces apoptosis through down-regulation of Src, ERK, and Akt survival signaling in human colon cancer cells. J Cell Biochem 2005; 96(1): 155-69.

[26] Jarry H, Spengler B, Porzel A, Schmidt J, Wuttke W, Christoffel V. Evidence for estrogen receptor beta-selective activity of Vitex agnus-castus and isolated flavones. Planta Med 2003; 69(10): 945-7.

[27] Liu J, Burdette JE, Xu H, et al. Evaluation of estrogenic activity of plant extracts for the potential treatment of menopausal symptoms. J Agric Food Chem 2001; 49(5): 2472-9.

[28] Ohyama K, Akaike T, Imai M, Toyoda H, Hirobe C, Bessho T. Human gastric signet ring carcinoma (KATO-III) cell apoptosis induced by Vitex agnus-castus fruit extract through intracellular oxidative stress. Int J Biochem Cell Biol 2005; 37(7): 1496-510.

[29] Ohyama K, Akaike T, Hirobe C, Yamakawa T. Cytotoxicity and apoptotic inducibility of Vitex agnus-castus fruit extract in cultured human normal and cancer cells and effect on growth. Biol Pharm Bull 2003; 26(1): 10-8.

[30] Wang H, Ye X, Gao Q, et al. Pharmacovigilance in Traditional Chinese Medicine safety surveillance. Pharmacoepidemiol Drug Saf 2009; 18(5): 357-61.

[31] Park S, Lee DK, Yang CH. Inhibition of fos-jun-DNA complex formation by dihydroguaiaretic acid and in vitro cytotoxic effects on cancer cells. Cancer Lett 1998; 15; 127(1-2): 23-8.

[32] Spiller HA, Winter ML, Weber JA, Krenzelok EP, Anderson DL, Ryan ML. Skin breakdown and blisters from senna-containing laxatives in young children. Ann Pharmcother 2003; 37(5): 636-9.

[33] Feres M, Figueiredo LC, Barreto IM, Coelho MH, Araujo MW, Cortelli SC. In vitro antimicrobial activity of plant extracts and propolis in saliva samples of healthy and periodontally-involved subjects. J Int Acad Periodontol 2005; 7(3): 90-6.

[34] Tildesley NT, Kennedy DO, Perry EK, Ballard CG, Wesnes KA, Scholey AB. Positive modulation of mood and cognitive performance following administration of acute doses of Salvia lavandulae- folia essential oil to healthy young volunteers. Physiol Behav 2005; 83(5): 699-709.

[35] Perry NS, Bollen C, Perry EK, Ballard C. Salvia for dementia therapy: review of pharmacological activity and pilot tolerability clinical trial. Pharmacol Biochem Behav 2003; 75(3): 651-9.

[36] Gali-Muhtasib H, Himan C, Khater C. Traditional uses of Salvia libanotica (East Mediterranean sage) and the effects of its essential oils. J Ethanopharmacol 2000; 71(3): 513-20.

[37] Kennedy DO, Pace S, Haskell C, Okello EJ, Milne A, Scholey AB. Effects of cholinesterase inhibiting sage (Salvia officinalis) on mood, anxiety and performance on a psychological stressor battery. Neuropsychopharmacology 2006; 31(4): 845-52.

[38] Dörrie J, Sapala K, Zunino SJ. Carnosol-induced apoptosis and downregulation of Bcl-2 in B-lineage leukemia cells. Cancer Lett 2001; 170(1): 33-9.

[39] Plouzek CA, Ciolino HP, Clarke R, Yeh GC. Inhibition of Pglycoprotein activity and reversal of multidrug resistance in vitro by rosemary extract. Eur J Cancer 1999; 35(10): 1541-5.

[40] Zhao W, Wang Y, Tang FD, et al. Zhongguo Zhong Yao Za Zhil 2006; 31(4): 319-22.

[41] Warnke PH, Sherry E, Russo PAJ, et al. Antibacterial essential oils in malodorous cancer patients: clinical observations in 30 patients. Phytomedicne 2006; 13(7): 463-7.

[42] Heptinstall S, White A, Williamson L, Mitchell JR. Extracts of feverfew inhibit granule secretion in blood platelets and polymorphonuclear leucocytes. Lancet 1985; 1(8437): 1071-4.

[43] Dwivedi C, Abhu-Ghazaleh A. Chemopreventive effects of sandalwood oil on skin papillomas in mice. Eur J Cancer Prev 1997; 6(4): 399-401.

[44] Panciera RJ, Martin T, Burrows GE, Taylor DS, Rice LE Acute oxalate poisoning attributable to ingestion of curly dock (Rumex crispus) in sheep. J Am Vet Med Assoc 1990; 196(12): 1981-4.

[45] Yamaguchi K, Liggett JL, Kim NC, Baek SJ. Anti-proliferative effect of horehound leaf and wild cherry bark extracts on human colorectal cancer cells. Oncol Rep 2006; 15(1): 275-81.

[46] Chang JS, Liu HW, Wang KC, et al. Ethanol extract of Polygonum cuspidatum inhibits hepatitis B virus in a stable HBV-producing cell line. Antiviral Res 2005; 66(1): 29-34.

[47] Lee EB, Kim OJ, Kang SS, Jeong C Araloside A. An antiulcer constituent from the root bark of Aralia elata. Biol Pharm Bull 2005; 28(3): 523-6.

[48] Banerjee S, Bueso-Ramos C, Aggarwal BB. Suppression of 7, $12-$ dimethylbenz(a)anthracene-induced mammary carcinogenesis in rats by resveratrol: role of nuclear factor-kappaB, cyclooxygenase 2, and matrix metalloprotease 9. Cancer Res 2002; 62(17): 494554.

[49] Paulsen E. Contact sensitization from Compositae-containing herbal remedies and cosmetics. Contact Dermatitis 2002; 47(4): 189-98.

[50] Smith MC, Holcombe JK, Stullenbarger E. A meta-analysis of intervention effectiveness for symptom management in oncology nursing research. Oncol Nurs Forum 1994; 21(7): 1201-10.

[51] Wei QY, Ma JP, Cai YJ, Yang L, Liu ZL. Cytotoxic and apoptotic activities of diarylheptanoids and gingerol-related compounds from the rhizome of Chinese ginger. J Ethnopharmacol 2005; 102(2): 177-84.

[52] Chun KS, Park KK, Lee J, Kang M, Surh YJ. Inhibition of mouse skin tumor promotion by anti-inflammatory diarylheptanoids derived from Alpinia oxyphylla Miquel (Zingiberaceae). Oncol Res 2002; 13(1): 37-45.

[53] Boone SA, Shields KM. Treating pregnancy-related nausea and vomiting with ginger. Ann Pharmacother 2005; 39(10): 1710-3

[54] Zhou HL, Deng YM, Xie QM. The modulatory effects of the volatile oil of ginger on the cellular immune response in vitro and in vivo in mice. J Ethnopharmacol 2006 21; 105(1-2): 301-5.

[55] Schoene NW, Kelly MA, Polansky MM, Anderson RA. Watersoluble polymeric polyphenols from cinnamon inhibit proliferation and alter cell cycle distribution patterns of hematologic tumor cell lines. Cancer Lett 2005; 230(1): 134-40.

[56] Gurley BJ, Swain A, Barone GW, et al. Effect of goldenseal(Hydrastis Canadensis) and kava kava (Piper methysticum) supplementation on digoxin pharmacokinetics in humans. Drug Metab Dispos 2007; 35(2): 240-5.

[57] Mazzio E, Soliman K. Nutraceutical Composition and Method of use for treatment / prevention of cancer US patent 2007/0248693. 
[58] Brown J, O'Prey J, Harrison PR. Enhanced sensitivity of human oral tumours to the flavonol, morin, during cancer progression: involvement of the Akt and stress kinase pathways. Carcinogenesis 2003; 24(2): 171-7.

[59] Boege F, Straub T, Kehr A, et al. Selected novel flavones inhibit the DNA binding or the DNA religation step of eukaryotic topoisomerase I. J Biol Chem 1996; 271(4): 2262-70).

[60] Ikegawa T, Ohtani H, Koyabu N, et al. Inhibition of P-glycoprotein by flavonoid derivatives in adriamycin-resistant human myelogenous leukemia (K562/ADM) cells. Cancer Lett 2002; 177(1): 89-93.

[61] Shishodia S, Aggarwal BB. Diosgenin inhibits osteoclastogenesis, invasion, and proliferation through the downregulation of $\mathrm{Akt}, \mathrm{I}$ kappa B kinase activation and NF-kappa B-regulated gene expression. Oncogene 2006; 25(10): 1463-73.

[62] Hostanska K, Daum G, Saller R. Cytostatic and apoptosis-inducing activity of boswellic acids toward malignant cell lines in vitro. Anticancer Res 2002; 22(5): 2853-62.

[63] Reanmongkol W, Tohda M, Matsumoto K, et al. Inhibitory effect of alkaloids extracted from the stem bark of Hunteria zeylanica on 5-lipoxygenase activity in vitro. Biol Pharm Bull 1995; 18(6): 9102.

[64] Sun Z, Sood S, Li N, et al. Involvement of the 5-lipoxygenase/ leukotriene A4 hydrolase pathway in 7, 12-dimethylbenz[a] anthracene (DMBA)-induced oral carcinogenesis in hamster cheek pouch, and inhibition of carcinogenesis by its inhibitors. Carcinogenesis 2006; 27(9): 1902-8

[65] Liao CH, Sang S, Ho CT, Lin JK. Garcinol modulates tyrosine phosphorylation of FAK and subsequently induces apoptosis through down-regulation of Src, ERK, and Akt survival signaling in human colon cancer cells. J Cell Biochem 2005; 96(1): 15569.

[66] Yamaguchi K, Liggett JL, Kim NC, Baek SJ. Anti-proliferative effect of horehound leaf and wild cherry bark extracts on human colorectal cancer cells. Oncol Rep 2006; 15(1): 275-81.

[67] Gurley BJ, Swain A, Barone GW, et al. Cheboyina S. Effect of goldenseal (Hydrastis canadensis) and kava kava (Piper methysticum) supplementation on digoxin pharmacokinetics in humans. Drug Metab Dispos 2007; 35(2): 240-5.

[68] Condori J, Medrano G, Sivakumar G, Nair V, Cramer C, MedinaBolivar F. Functional characterization of a stilbene synthase gene using a transient expression system in planta. Plant Cell Rep 2009; 28(4): 589-99.

[69] Sharma R. Nutraceuticals and nutraceutical supplementation criteria in cancer: a literature survey. Open Nutraceuticals J 2009; 2(2): 92-106.

This is an open access article licensed under the terms of the Creative Commons Attribution Non-Commercial License (http://creativecommons.org/licenses/ by-nc/3.0/) which permits unrestricted, non-commercial use, distribution and reproduction in any medium, provided the work is properly cited. 